\title{
Risk evaluation of tailings dam-break based on the extension matter-element model
}

\author{
Congcong Chen ${ }^{* 1, a}, \mathrm{Bo} \mathrm{Ma}^{1, \mathrm{~b}}$ \\ ${ }^{1}$ School of Civil and Resource Engineering University of Science and Technology Beijing 100083 Beijing, China
}

\begin{abstract}
As one of the most concerned risk sources of mining enterprises, the safety and stability of the tailings storage facility (TSF) is closely connected to the operating activity, surrounding ecological environment, and residents' lives safety and properties safety. In order to evaluate the risk of the tailings dam break, the extension matter-element model has been applied in the work. First, the risk evaluation indicator system was established, included 3 levels, 4 criteria and 17 individual indicators. Next, the weight of each indicator was computed by using the analytic hierarchy process (AHP) method. Then, the classical field, controlled field and closeness function within the extension matter-element model were determined considering the TSF height and volume, and the principle of the maximum membership degree has been improved by the closeness. Finally, a case study was illustrated to demonstrate the effectiveness of the model. The result indicated that the target TSF operated at a relatively lower risk level, which accurately reflected the real operating situation. This work can provide a reasonable reference for dam break risk evaluation.
\end{abstract}

\section{Introduction}

This Tailings is one of the waste byproducts of mining and mineral processing, from which the useful minerals have been extracted. The tailings storage facility (TSF) is a complicated geotechnical engineering structure, which is surrounded by natural heights and/or artificial walls and used to store tailings [1]. Its ultimate purpose is to provide safety, stable, erosion-resistant, non-polluting and economical storage of fine-grained tailings, often with a secondary or co-purpose of conserving water for use in the mine and mill. Therefore, it is obvious that the safety and stability of the whole structure is critical.

In recent years, the hazards of TSF have become increasingly prominent. There have been many TSF accidents around the world [2,3], according to statistics, about 130 TSF accidents have occurred around the world since 1960 [4]. The consequences involve irreversible surrounding ecological damage and environment damage, lives and properties loss and even social instability $[5,6]$. For example, one of the most publicized TSF dam break is the accident that occurred on 8 September 2008, in Xiangfen County, Shanxi Province, China, with 281 deaths, 33 injuries and a direct economic loss of 96.19 million RMB, has been the most tragic reported failure in China so far [7]. On November 5, 2015, Samarco's Fundão tailings dam in Brazil suddenly collapsed. This incident generated 50-60 million cubic meters of mine tailings into the Gualaxo do Norte, resulted in three communities flooded and 19 loss of lives, and affected the biodiversity across hundreds of kilometers of water, which is considered to be the largest environmental disaster of this type in recent years [8-12]. As a dangerous source of manmade debris flow with high potential energy, the risk evaluation of tailings dam break is a fundamental and practical way to anticipate potential problems and issues.

Up to now, many risk evaluation approaches have been generated, such as the AHP, uncertain measurement, back propagation neural network, fuzzy theory, leading to numerous meaningful research results [13-16]. Majority of contributions in this research field only focused on the qualitative perspective or the quantitative one, and failed to solve the problem of risk evaluation from both the qualitative and quantitative perspective. To make up for this research deficiency, this work adopt extension matterelement model combined with AHP method to evaluate the risk of the tailings dam break. The extension matterelement model established by Chinese scholar W Cai [17] could deal effectively with the intrinsic multidimensionality, complexity and subjectivity of risk evaluation problems. And, the qualitative indicators are able to quantified conveniently by this model. Accordingly, the extension matter-element model is an ideal model for risk evaluation of the tailings dam break.

\section{Extension matter-element model for risk evaluation of the tailings dam break}

\subsection{Selecting a Template (Heading 2) Indicator system of risk evaluation}

Establishing an accurate, comprehensive and effective indicator system is the foundation for risk evaluation of the tailings dam break. Given the complicated and variable

\footnotetext{
a* Corresponding author: chencong0428@126.com

bNuh8022314@163.com
} 
characteristics of the influencing factors, indicators from initiatives, standards, and former literature [18-24] are referred and reorganized in this work. The risk evaluation indicator system for the tailings dam break is divided into four major criteria: human factor, technology factor, environment factor and management factor, and each criterion is consisted of several individual indicators, shown in Fig 1.

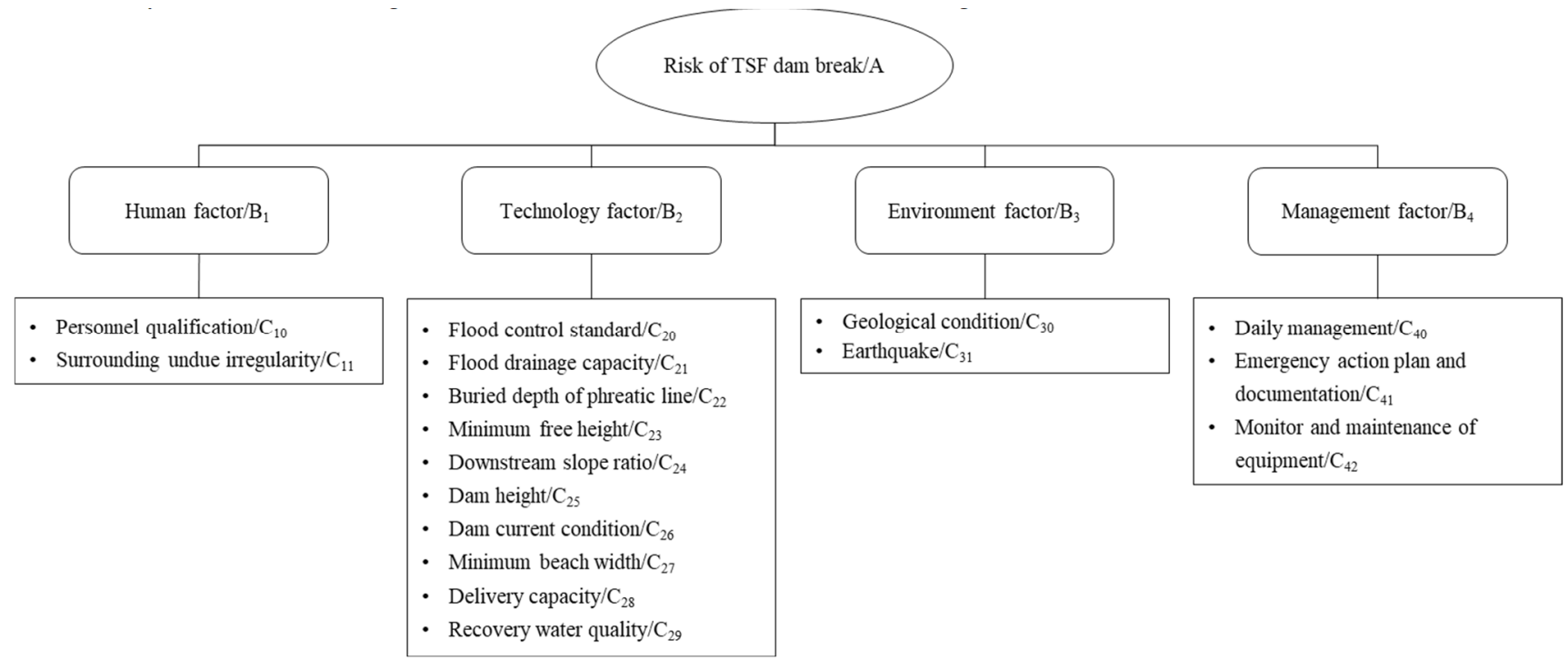

Fig1. Risk evaluation indicator system for the tailings dam break

\subsection{Extension matter-element evaluation model}

The extension set theory and the matter-element method are the theoretical pillars of the extension theory. The matter-element model is comprised of objects, characteristics and values based on certain characteristics, so as to describe the contents and relationships among evaluation items. The idea of extension matter-element model is that, firstly, the evaluation object (the risk of the tailings dam break) is divided into four levels (lower, low, high, higher) according to existing data and the ranges of data at all levels are given by database or expert opinions. Then a multi-indicator system is measured through inducing the indicators of evaluation objects into the set of each level. The evaluation results are determined according to the value of the closeness function. The greater the degree of closeness is, the better the degree of coincidence is. The specific steps of the evaluation model are shown as follows [25].

\section{Step1 Basic definition}

Suppose object $N$ has $n$ characteristics $c_{1}, c_{2}, \ldots, c_{n}$ and the corresponding values $v_{l}, v_{2}, \ldots, v_{n}$. Then matterelement $\mathrm{R}$ is named $\mathrm{n}$-dimensional matter-element, shown as:

$$
R=(N, C, V)=\left[\begin{array}{c}
R_{1} \\
R_{2} \\
\vdots \\
R_{n}
\end{array}\right]=\left[\begin{array}{ccc}
N & c_{1} & v_{1} \\
& c_{2} & v_{2} \\
& \vdots & \vdots \\
& c_{n} & v_{n}
\end{array}\right]
$$

where $R_{i}$ is the sub-matter-element of $R, C$ is the eigenvector, $V$ is the value of the eigenvector.

Step 2 Determine the matter-element to be evaluated, the classical field and controlled field

Suppose

$$
R_{0}=\left[\begin{array}{ccc}
N_{0} & c_{1} & v_{1} \\
& c_{2} & v_{2} \\
& \vdots & \vdots \\
& c_{n} & v_{n}
\end{array}\right]
$$

where $N_{0}$ is the matter-element to be evaluated and $v_{l}$, $v_{2}, \ldots, v_{n}$ are the detected concrete data of $N_{0}$ about $c_{l}$, $c_{2}, \ldots, c_{n}$ respectively.

Suppose

$$
R_{j}=\left[\begin{array}{ccc}
N_{j} & c_{1} & v_{j 1} \\
& c_{2} & v_{j 2} \\
\vdots & \vdots \\
& c_{n} & v_{j n}
\end{array}\right]=\left[\begin{array}{ccc}
N_{j} & c_{1} & <a_{j 1}, b_{j 1}> \\
& c_{2} & <a_{j 2}, b_{j 2}> \\
\vdots & \vdots \\
& c_{n} & <a_{j n}, b_{j n}>
\end{array}\right]
$$

where $N_{j}$ is the $j$ levels, $c_{1}, c_{2}, \ldots, c_{n}$ are $n$ different characteristics of $N_{j}$, and $v_{j l}, v_{j 2}, \ldots, v_{j n}$ are respectively the value ranges of $N_{j}$ about $c_{1}, c_{2}, \ldots, c_{n}$, that is the classical field.

$$
R_{p}=\left[\begin{array}{ccc}
N_{p} & c_{1} & v_{p 1} \\
& c_{2} & v_{p 2} \\
& \vdots & \vdots \\
& c_{n} & v_{p n}
\end{array}\right]=\left[\begin{array}{ccc}
N_{p} & c_{1} & <a_{p 1}, b_{p 1}> \\
& c_{2} & <a_{p 2}, b_{p 2}> \\
\vdots & \vdots \\
& c_{n} & <a_{p n}, b_{p n}>
\end{array}\right]
$$

where $N_{p}$ is all the levels of objects to be assessed, and $v_{p l}$, $v_{p 2}, \ldots, v_{p n}$ are the value ranges of $N_{p}$ about $c_{1}, c_{2}, \ldots, c_{n}$, namely the controlled field of $N_{p}$ respectively.

One of the foundations of the risk evaluation of the TSF dam break is the determination of the classical field. With reference to previous existing documents, the risk is divided into four levels, namely $\mathrm{L}_{1}$ (Lower risk), $\mathrm{L}_{2}$ (Low risk), $\mathrm{L}_{3}$ (High risk), $\mathrm{L}_{4}$ (Higher risk). The specific value ranges of the classic field and the controlled field are shown in Table 1. 
Table1. The range of individual indicator for TSF dam break

\begin{tabular}{|c|c|c|c|c|c|c|}
\hline \multirow{2}{*}{ Individual indicator } & \multirow{2}{*}{$\begin{array}{c}\text { TSF grade/ } \\
\text { (I-V) }\end{array}$} & \multicolumn{4}{|c|}{ Range of classical field } & \multirow{2}{*}{$\begin{array}{c}\text { Rang of controlled } \\
\text { field } \\
\end{array}$} \\
\hline & & $L_{1}$ & $L_{2}$ & $L_{3}$ & $L_{4}$ & \\
\hline $\mathrm{C}_{10}$ & $\mathrm{I}-\mathrm{V}$ & $0.75-1$ & $0.5-0.75$ & $0.25-0.5$ & $0-0.25$ & $0-1$ \\
\hline $\mathrm{C}_{11}$ & $\mathrm{I}-\mathrm{V}$ & $0.75-1$ & $0.5-0.75$ & $0.25-0.5$ & $0-0.25$ & $0-1$ \\
\hline \multirow{5}{*}{$\mathrm{C}_{20}$} & $\mathrm{I}$ & $2000-2500$ & $1500-2000$ & $1000-1500$ & $500-1000$ & $500-2500$ \\
\hline & II & $1000-1250$ & $750-1000$ & $500-750$ & $250-500$ & $250-1250$ \\
\hline & III & $500-650$ & $350-500$ & $200-350$ & $100-200$ & $100-650$ \\
\hline & IV & $200-250$ & $150-200$ & $100-150$ & $50-100$ & $50-250$ \\
\hline & $\mathrm{V}$ & $100-125$ & $75-100$ & $50-75$ & $25-50$ & $25-125$ \\
\hline $\mathrm{C}_{21}$ & $\mathrm{I}-\mathrm{V}$ & $30-50$ & $50-72$ & $72-76$ & $76-80$ & $30-80$ \\
\hline \multirow{5}{*}{$\mathrm{C}_{22}$} & $\mathrm{I}$ & $4.5-6.0$ & $3-4.5$ & $1.5-3$ & $0-1.5$ & $0-6.0$ \\
\hline & II & $4-4.5$ & $2.5-4$ & $1-2.5$ & $0-1$ & $0-4.5$ \\
\hline & III & $3.7-4$ & $2.2-3.7$ & $0.7-2.2$ & $0-0.7$ & $0-4$ \\
\hline & IV & $3.5-3.7$ & $2-3.5$ & $0.5-2$ & $0-0.5$ & $0-3.7$ \\
\hline & $\mathrm{V}$ & $3.4-3.5$ & $1.9-3.4$ & $0.4-1.9$ & $0-0.4$ & $0-3.5$ \\
\hline \multirow{4}{*}{$\mathrm{C}_{23}$} & $\begin{array}{c}\text { Dam height } \\
5-10 \mathrm{~m}\end{array}$ & $2-2.5$ & $1.875-2$ & $1.75-1.875$ & $0-1.725$ & $0-2.5$ \\
\hline & $\begin{array}{c}\text { Dam height } \\
10-20 \mathrm{~m}\end{array}$ & $2.5-3$ & $2.25-2.5$ & $2-2.5$ & $0-2$ & $0-3$ \\
\hline & $\begin{array}{c}\text { Dam height } \\
20-30 \mathrm{~m}\end{array}$ & $3-3.5$ & $2.75-3$ & $2.5-2.75$ & $0-2.5$ & $0-3.5$ \\
\hline & $\begin{array}{c}\text { Dam height } \\
>30 \mathrm{~m}\end{array}$ & $4-5$ & $3.5-4$ & $3-3.5$ & $0-3$ & $0-5$ \\
\hline \multirow{4}{*}{$\mathrm{C}_{24}$} & I-II & $130-150 \mathrm{~m}$ & $113-130$ & $100-113$ & $0-100$ & $0-150$ \\
\hline & III & $100-120 \mathrm{~m}$ & $80-100$ & $60-80$ & $0-60$ & $0-120$ \\
\hline & IV & $60-75 \mathrm{~m}$ & $45-60$ & $30-45$ & $0-30$ & $0-75$ \\
\hline & $\mathrm{V}$ & $30-40 \mathrm{~m}$ & $22.5-30$ & $15-22.5$ & $0-15$ & $0-40$ \\
\hline $\mathrm{C}_{25}$ & $\mathrm{I}-\mathrm{V}$ & $0.75-1$ & $0.5-0.75$ & $0.25-0.5$ & $0-0.25$ & $0-1$ \\
\hline $\mathrm{C}_{26}$ & $\mathrm{I}-\mathrm{V}$ & $0.75-1$ & $0.5-0.75$ & $0.25-0.5$ & $0-0.25$ & $0-1$ \\
\hline \multirow{5}{*}{$\mathrm{C}_{27}$} & $\mathrm{I}$ & $250-300$ & $200-250$ & $150-200$ & $0-150$ & $0-300$ \\
\hline & II & $180-220$ & $140-180$ & $100-140$ & $0-100$ & $0-220$ \\
\hline & III & $130-160$ & $100-130$ & $70-100$ & $0-70$ & $0-160$ \\
\hline & IV & $90-110$ & $70-90$ & $50-70$ & $0-50$ & $0-110$ \\
\hline & $\mathrm{V}$ & $60-70$ & $50-60$ & $40-50$ & $0-40$ & $0-70$ \\
\hline $\mathrm{C}_{28}$ & $\mathrm{I}-\mathrm{V}$ & $0.75-1$ & $0.5-0.75$ & $0.25-0.5$ & $0-0.25$ & $0-1$ \\
\hline $\mathrm{C}_{29}$ & $\mathrm{I}-\mathrm{V}$ & $0.75-1$ & $0.5-0.75$ & $0.25-0.5$ & $0-0.25$ & $0-1$ \\
\hline $\mathrm{C}_{30}$ & $\mathrm{I}-\mathrm{V}$ & $0.8-1$ & $0.35-0.8$ & $0.05-0.35$ & $0-0.05$ & $0-1$ \\
\hline $\mathrm{C}_{31}$ & $\mathrm{I}-\mathrm{V}$ & $0-5.9$ & $5.9-7$ & $7-8$ & $8-10$ & $0-10$ \\
\hline $\mathrm{C}_{40}$ & $\mathrm{I}-\mathrm{V}$ & $0.75-1$ & $0.5-0.75$ & $0.25-0.5$ & $0-0.25$ & $0-1$ \\
\hline $\mathrm{C}_{41}$ & $\mathrm{I}-\mathrm{V}$ & $0.75-1$ & $0.5-0.75$ & $0.25-0.5$ & $0-0.25$ & $0-1$ \\
\hline $\mathrm{C}_{42}$ & $\mathrm{I}-\mathrm{V}$ & $0.75-1$ & $0.5-0.75$ & $0.25-0.5$ & $0-0.25$ & $0-1$ \\
\hline
\end{tabular}

\section{Step 3 Normalization}

However, if the quantified value of any indicator exceeds the controlled field, it will be unable to be calculated. In this case, the matter-element and extension model cannot be used to evaluate the risk levels involved. On the account, the extension matter-element model has been improved, in order to resolve this limitation [26]. This has been done as follows.

$$
R_{0}^{\prime}=\left[\begin{array}{ccc}
N_{0} & c_{1} & \frac{v_{1}}{b_{p 1}} \\
& c_{2} & \frac{v_{2}}{b_{p 2}} \\
\vdots & \vdots \\
& c_{n} & \frac{v_{n}}{b_{p n}}
\end{array}\right]_{(5)} \quad R_{j}^{\prime}=\left[\begin{array}{ccc}
N_{j} & c_{1} & <\frac{a_{j 1}}{b_{p 1}}, \frac{a_{j 1}}{b_{p 1}}> \\
c_{2} & <\frac{a_{j 2}}{b_{p 2}}, \frac{a_{j 2}}{b_{p 2}}> \\
\vdots & \vdots \\
c_{n} & <\frac{a_{j n}}{b_{p n}}, \frac{a_{j n}}{b_{p n}}>
\end{array}\right]_{(6)}
$$

Step 4 Closeness calculation

$$
\begin{aligned}
& D_{j}\left(v_{i}^{\prime}\right)=\left|v_{i}^{\prime}-\frac{a_{j i}^{\prime}+b_{j i}^{\prime}}{2}\right|-\frac{1}{2}\left(b_{j i}^{\prime}-a_{j i}^{\prime}\right) \\
& P_{j}\left(R_{0}^{\prime}\right)=1-\frac{1}{n(n+1)} \sum_{i=1}^{n} D_{j}\left(v_{i}^{\prime}\right) \omega_{i}(X)
\end{aligned}
$$

where $D_{j}\left(v_{i}^{\prime}\right)$ is the distance of the normalized matterelement evaluation relative to the normalized classical field, $P_{j}\left(R_{0}{ }^{\prime}\right)$ is the comprehensive closeness of the $j$ level, $\omega_{\mathrm{i}}(\mathrm{X})$ is the indicator weight, $\mathrm{n}$ is the number of indicators.

Step 5 Level determination

Suppose

$$
P_{m}\left(R_{0}^{\prime}\right)=\max \left[P_{j}\left(R_{0}^{\prime}\right)\right]
$$

where the matter-element to be evaluated $R_{0}$ is belonged to the $\mathrm{m}$ level.

$$
\bar{P}_{j}\left(R_{0}^{\prime}\right)=\frac{P_{j}\left(R_{0}^{\prime}\right)-\min \left[P_{j}\left(R_{0}^{\prime}\right)\right]}{\max \left[P_{j}\left(R_{0}^{\prime}\right)\right]-\min \left[P_{j}\left(R_{0}^{\prime}\right)\right]}
$$

where $\max \left[\mathrm{P}_{\mathrm{j}}\left(\mathrm{R}_{0}{ }^{\prime}\right)\right]$ represents the maximum of correlation degree in all levels, $\min \left[\mathrm{P}_{\mathrm{j}}\left(\mathrm{R}_{0}{ }^{\prime}\right)\right]$ represents the minimum of correlation degree in all levels.

$$
j^{*}=\frac{\sum_{j=1}^{m} j \bar{P}_{j}\left(R_{0}^{\prime}\right)}{\sum_{j=1}^{m} \bar{P}_{j}\left(R_{0}^{\prime}\right)}
$$

where $j^{*}$ is the risk level variable eigenvalue of $R_{0}$. The attributive degree of the evaluated matter-element tend to adjacent levels can be judged from $\mathrm{j}^{*}$. 


\section{Case study}

\subsection{Project overview}

Shandong Laiwu Luzhong mining company limited has operated for over 30 years. Yujiaquan tailings pond put into operation synchronously with the company, is located 8-12 kilometers north of Laiwu City. There is no harmful geological effect in the study area, such as landslides, avalanches, mud-rock flow, surface subsidence, fall of ground. The Laiwu region is situated at the continental semi-humid monsoon climate in warm temperate zone, with low rainfall intensity, averaging $760.9 \mathrm{~mm}$ for many years.

The starter dam of the TSF is constructed by rock and 30 meters high, the accumulation dam is filled upstream style by tailings, which has been widely used in China. Flood drainage system adopts the form of both the drainage well and bottom drainage pipe, and eight drainage wells are set up altogether. The present drainage system is well structured and can meet the requirement of normal backwater and flood control. The TSF has played a good role in reducing the buried depth of the phreatic line in the dam by using waste rock to construct wide subdam. In view of the TSF safety management, the relevant facilities and equipment in the surrounding area are under good condition, satisfying the requirements of daily operation and management. In summary, it is implemented in the actual safety production management and meets the safety management requirements.

\subsection{Determine the matter-element to be evaluated}

According to the engineering background of Yujiaquan TSF, referring to relevant design, construction, and evaluation documents, the value of each indicator is determined, shown in Table 2.

Table2. Indicator value of Yujiaquan TSF

\begin{tabular}{|c|c|c|c|c|c|c|c|c|c|}
\hline Indicator & $\mathrm{C}_{10}$ & $\mathrm{C}_{11}$ & $\mathrm{C}_{20}$ & $\mathrm{C}_{21}$ & $\mathrm{C}_{22}$ & $\mathrm{C}_{23}$ & $\mathrm{C}_{24}$ & $\mathrm{C}_{25}$ & $\mathrm{C}_{26}$ \\
\hline $\begin{array}{c}\text { Original } \\
\text { value }\end{array}$ & 0.75 & 0.8 & 1000 & 30 & 0.7 & 5 & $1: 4.0$ & 82 & 0.85 \\
\hline Indicator & $\mathrm{C}_{27}$ & $\mathrm{C}_{28}$ & $\mathrm{C}_{29}$ & $\mathrm{C}_{30}$ & $\mathrm{C}_{31}$ & $\mathrm{C}_{40}$ & $\mathrm{C}_{41}$ & $\mathrm{C}_{42}$ & \\
\hline $\begin{array}{c}\text { Original } \\
\text { value }\end{array}$ & 800 & 0.9 & 0.75 & 0.8 & 3 & 0.85 & 0.75 & 0.9 & \\
\hline
\end{tabular}

\subsection{Compute the indicator weight}

The risk evaluation indicator system of the tailings dam break involves three levels: target level, criterion level, and individual indicator level. The degree of influence of each level and each individual indicator on the risk level is also different. Analytic hierarchy process (AHP) developed by Saaty [26] has been ever favorable among multi-criteria decision-making methods, mainly due to its understandability in theory and the simplicity in application [27]. AHP has been deal with such hierarchy structure than can combine both quantitative (objective) and qualitive (subjective) indicators. Therefore, AHP method is applied to calculate the indicator weight of the tailings dam break, the specific steps are omitted, the results are shown in Table 3 .
Table3. Calculation results of indicator weight

\begin{tabular}{|l|l|}
\hline \multicolumn{1}{|c|}{ Individual indicator } & \multicolumn{1}{c|}{ Constant weight } \\
\hline$\left(\mathrm{C}_{10}, \mathrm{C}_{11}\right)$ & $(0.201,0.067)$ \\
\hline$\left(\mathrm{C}_{20}, \mathrm{C}_{21}, \mathrm{C}_{22}, \mathrm{C}_{23}, \mathrm{C}_{24}, \mathrm{C}_{25}, \mathrm{C}_{26}\right.$, & $(0.013,0.036,0.017,0.020,0.005$, \\
$\left.\mathrm{C}_{27}, \mathrm{C}_{28}, \mathrm{C}_{29}\right)$ & $0.013,0.005,0.011,0.004,0.003)$ \\
\hline$\left(\mathrm{C}_{30}, \mathrm{C}_{31}\right)$ & $(0.049,0.024)$ \\
\hline$\left(\mathrm{C}_{40}, \mathrm{C}_{41}, \mathrm{C}_{42}\right)$ & $(0.287,0.087,0.158)$ \\
\hline
\end{tabular}

\subsection{Calculate closeness and determine risk level}

According to the established matter-element evaluation model, the distance of each indicator is calculated, as shown in Table 4 . Then according to equations (2-7) to calculate the closeness of the object $R_{0}$ to each evaluation level.

$$
\begin{aligned}
& P_{1}\left(R_{0}^{\prime}\right)=1-\frac{1}{17 \times 18} \sum_{i=1}^{n} D_{j}\left(v_{i}^{\prime}\right) \omega_{i}(X)=0.9967 \\
& P_{2}\left(R_{0}^{\prime}\right)=1-\frac{1}{17 \times 18} \sum_{i=1}^{n} D_{j}\left(v_{i}^{\prime}\right) \omega_{i}(X)=0.8579 \\
& P_{3}\left(R_{0}^{\prime}\right)=1-\frac{1}{17 \times 18} \sum_{i=1}^{n} D_{j}\left(v_{i}^{\prime}\right) \omega_{i}(X)=0.5878 \\
& P_{4}\left(R_{0}^{\prime}\right)=1-\frac{1}{17 \times 18} \sum_{i=1}^{n} D_{j}\left(v_{i}^{\prime}\right) \omega_{i}(X)=0.3328
\end{aligned}
$$

After determining the closeness of the object $R_{0}$ towards each evaluation level, obviously, $P_{1}\left(R_{0}^{\prime}\right)=\max \left\{P_{j}\left(R_{0}^{\prime}\right)\right\}=0.9967$. Then, according to equations $(2-10), j^{*}=1.717>1.5$. Therefore, the risk level of the TSF is $\mathrm{L}_{1}$, the risk is relatively lower, and the degree of bias toward $\mathrm{L}_{2}$ level is larger.

Table4. The distance value $\mathrm{D}_{\mathrm{j}}\left(\mathrm{v}_{\mathrm{i}}^{\prime}\right)$ of the indicator for the tailings dam break

\begin{tabular}{|c|c|c|c|c|}
\hline $\begin{array}{c}\text { Individual } \\
\text { indicator }\end{array}$ & $\boldsymbol{D}_{\boldsymbol{1}}\left(\boldsymbol{v}_{\boldsymbol{i}}^{\prime}\right)$ & $\boldsymbol{D}_{2}\left(\boldsymbol{v}_{\boldsymbol{i}}^{\prime}\right)$ & $\boldsymbol{D}_{3}\left(\boldsymbol{v}_{\boldsymbol{i}}^{\prime}\right)$ & $\boldsymbol{D}_{4}\left(\boldsymbol{v}_{\boldsymbol{i}}^{\prime}\right)$ \\
\hline $\mathrm{C}_{10}$ & 0 & 0 & 0.25 & 0.5 \\
\hline $\mathrm{C}_{11}$ & -0.05 & 0.05 & 0.3 & 0.55 \\
\hline $\mathrm{C}_{20}$ & 0.54 & 0.76 & 1 & 1.23 \\
\hline $\mathrm{C}_{21}$ & 0 & 0.25 & 0.52 & 0.57 \\
\hline $\mathrm{C}_{22}$ & 0.25 & 0.32 & 0.7 & 1.07 \\
\hline $\mathrm{C}_{23}$ & 0 & 0 & 0.1 & 0.1 \\
\hline $\mathrm{C}_{24}$ & 0.15 & -0.01 & 0.01 & 0.18 \\
\hline $\mathrm{C}_{25}$ & -0.1 & 0.1 & 0.35 & 0.6 \\
\hline $\mathrm{C}_{26}$ & 0.05 & -0.05 & 0.2 & 0.45 \\
\hline $\mathrm{C}_{27}$ & 4 & 4.19 & 4.37 & 4.56 \\
\hline $\mathrm{C}_{28}$ & -0.1 & 0.15 & 0.4 & 0.65 \\
\hline $\mathrm{C}_{29}$ & 0 & 0 & 0.25 & 0.5 \\
\hline $\mathrm{C}_{30}$ & 0 & 0 & 0.45 & 0.75 \\
\hline $\mathrm{C}_{31}$ & -0.29 & 0.29 & 0.4 & 0.5 \\
\hline $\mathrm{C}_{40}$ & -0.1 & 0.1 & 0.35 & 0.6 \\
\hline $\mathrm{C}_{41}$ & 0 & 0 & 0.25 & 0.5 \\
\hline $\mathrm{C}_{42}$ & -0.1 & 0.15 & 0.4 & 0.65 \\
\hline
\end{tabular}

\section{Conclusions}

(1) In the paper, an improved extension matter-element model is applied and the grades of the TSF (first-fifthclass) is considered, a comprehensive risk evaluation model of the tailings dam break is finally established. By normalizing the classical field and the matter-element to be evaluated, and using the closeness principle to replace 
the maximum membership criterion, the limitations and deficiencies of the traditional extension matter-element model in risk evaluation have been overcome.

(2) Using this model to evaluate the risk of Yujiaquan TSF, the result shows that its risk level is $\mathrm{L}_{1}$ (lower risk), which is consistent with the actual operating situation.

(3) Indicators such as personnel qualification, daily management, and equipment monitoring and maintenance are worthy of much attention in the further safety management of the TSF and the tailings dam break.

\section{Acknowledgment}

This research was funded by the Chinese National Key Research and Development Program under grant number 2017YFC0804605.

\section{References}

1. J.S. Chai, S. Wang, and Y.S. Men, Cases analysis and accidents prediction of tailings ponds Chemical, Industry Press, Beijing, 2010.

2. S. Azam, Q. Li, "Tailings dam failures: A review of the last one hundred years," Geotechnical News, vol. 28, pp. 50-54, 2010.

3. M. Rico, G. Benito, A.R. Salguerio, A. Diez-Herrero, and H.G. Pereira, "Reported tailings dam failures: a review of the European incidents in the worldwide context," J. Hazard Mater., vol. 152, pp. 846-852, 2008.

4. WISE Uranium Project. Chronology of major tailings dam failure. https://www.wiseuranium.org/mdaf.html (Accessed on 5 May 2020).

5. D. Kossoff, W.E. Dubbin, M. Alfredsson, S.J. Edwards, M.G. Macklin, and K.A. Hudson-Edwards, "Mine tailings dams: characteristics, failure, environmental impacts, and remediation," Appl. Geochem., vol. 51, pp. 229-245, 2014.

6. G. Villavicencio, R. Espinace, J. Palma, A. Fourie, and P. Valenzuela, "Failures of sand tailings dams in a highly seismic country," Can. Geotech. J., vol. 51, pp. 449-464, 2014.

7. C.C. Shan, Z.D. Zhang, K.B. Zhong, and G.L. Shi, "Review and summary of handling process of Xiangfen '9.8' extremely major tailings dam break," China Emerg. Mgt., vol. 10, pp. 13-18, 2011.

8. L.C. Garcia, D.B. Ribeiro, F.O. Roque, J.M. OchoaQuintero, and W.F. Laurance, "Brazil's worst mining disaster: Corporations must be compelled to pay the actual environmental costs," 2016.

9. L.S. Miranda, and A.C. Marques, "Hidden impacts of the Samarco mining waste dam collapse to Brazilian marine fauna - an example from the staurozoans (Cnidaria)," Biota Neotrop., vol. 16, 2016.

10. A.C.O. Neves, F.P. Nunes, F.A. Carvalho, and G.W. Fernandes, "Neglect of ecosystems services by mining, and the worst environmental disaster in Brazil,” Brazilian J. Nat. Conserv., vol. 14, pp. 24-27,
2016.

11. F.R. Segura, E.A. Nunes, and F.P. Paniz, et al. "Potential risks of the residue from Samarco's mine dam burst (Bento Rodrigues, Brazil)," Environ. Pollut., vol. 218, pp. 813-825, 2016.

12. M.B.B. Guerra, B.T. Teaney, and B.J. Mount, et al. "Post-catastrophe analysis of the Fundão tailings dam failure in the Doce River System, Southeast Brazil: Potentially toxic elements in affected soils," Water, Air, \& Soil Pollut., vol. 228, pp. 252, 2017.

13. M.X. Qu, H. Wu, J. Gui, and Y. Liu, "Risk assessment of a tailings reservoir in Hubei based on fuzzy analytic hierarchy process," China Min. Mag., vol. 28, pp. 148-153, 2019.

14. K. Peng, X.B. Li, S.M. Wang, G.Y. Zhao, and Z.X. Liu, "Optimization model of unascertained measurement for dam-break risk evaluation in tailings dams," J. Central South Univ. (Sci. Tech.)., vol. 43, pp. 1447-1452, 2012.

15. Y.B. Wang, L. Wang, and Z.X. Li, "Safety evaluation of mine tailings facilities based on HS-BP algorithm," Sys. Eng.-Theory \& Pract., vol. 32, pp. 2585-2590, 2012.

16. K. Pan, K.L. Xu, and C. Liu, "Risk evaluation model of tailings pond based on the triangular fuzzy theory," J. Saf. Environ., vol. 12, pp. 242-245, 2012.

17. W. Cai, "The extension set and incompatible problem," Sci. Explor., vol. 3, pp. 83, 1983.

18. State Administration of Work Safety China, "Safety technical regulations for the tailing pond (AQ 20062005)", 2005.

19. State Administration of Work Safety China, "Safety supervision and management for the tailing pond", 2011.

20. State Administration of Work Safety China, "The applicable guide of standardized specification of work safety for tailings pond (AQ/T 2050.4-2016)", 2016.

21. State Administration of Work Safety China, "Technical regulations for the tailings pond safety monitoring (AQ 2030-2010)", 2010.

22. Ministry of Housing and Urban-Rural Development China, "Code for design of tailings facilities (GB 50863-2013)", 2013.

23. Y.D. Xu, W.F. Shi, J.C. Wu, W. He, and T. Luo, "Stability evaluation of tailing dam based on AHPextenics model," Nonfer. Met. Sci. Eng., vol. 7, pp. 94-98, 2016.

24. X.H. Wang, X.W. Gu, X.C. Xu, and Q. Wang, "Risk evaluation of break-dam in mine tailings pond based on GA-AHP and Cloud-Matter Element model", J. Northeast. Univ. (Nat. Sci.), vol. 38, pp. 1464-1467, 2017.

25. H.Z. Li, S. Guo, H. Tang, and C.J. Li, "Comprehensive evaluation on power quality based on improved matter-element extension model with variable weight," Power Sys. Tech., vol. 37, pp. 653659, 2013. 
26. T. L. Saaty, Multicriteria decision making: the analytic hierarchy process, Pittsburgh, RWS, 1988.

27. J. Wang, Y. Jing, C. Zhang, and J. Zhao, "Review on multi-criteria decision analysis aid in sustainable energy decision-making," Renew. Sust. Energ. Rev., vol. 13, pp. 2263-2278, 2009. 